\title{
Editorial
}

\section{The psychobiology of malnutrition in Brazil}

\author{
Sebastião Sousa Almeida and Silvio Morato \\ Universidade de São Paulo, Ribeirão Preto, Brazil
}

Luiz Marcellino de Oliveira, (Figure 1) Professor of the Departamento de Psicologia da Faculdade de Filosofia, Ciências e Letras de Ribeirão Preto da Universidade de São Paulo, died on May 08, 2008, in Ribeirão Preto, Brazil, at the age of 68 . He was a pioneer in the study of the effects of early protein malnutrition on brain and behavior in Brazil. He initiated his professional life teaching behavior analysis in the University of São Paulo, Ribeirão Preto, Brazil.

Luiz de Oliveira (the middle name Marcellino was adopted later) arrived in Ribeirão Preto in the early sixties, escaping from the military dictatorship persecution in Brasília, where he almost obtained his psychology diploma. He finished his studies in the Faculdade de Filosofia, Ciências e Letras de Ribeirão Preto, then an independent state school (later incorporated by the University of São Paulo), and was hired almost immediately after he graduated. He was in charge of the practicum of the psychology course, which included instructing the students on the various experiments, providing equipment, and maintaining a small animal room for the rats that came from the animal house in the campus.

All the experiments he programmed were under the strong influence of Fred S. Keller, his mentor at the Universidade de Brasília. Thus, the students got in contact with operant psychology and acquired a strong background in the experimental control of variables and on how to apply this to understand and analyze everyday situations. Luiz de Oliveira had a considerable influence on many of his students.

Also, he was the key factor in spreading operant behavior teaching when he opened the doors of the student laboratory he had created for psychology students of the medical and nursing schools. Former students acted as teaching assistants and behavioral laboratory exercises were performed by medical, nursing, and psychology students. This joint program was made possible by an agreement sealed by Luiz de Oliveira with the professors from the medical and nursing schools. This agreement was the seed of the Laboratory for Operant Behavior and Drugs, a large facility where professors, graduate and undergraduate students did behavioral research; it was located in the Faculdade de Filosofia, but the equipment came from several grants to the participant professors who, by then, belonged mainly to the Medical School and the Faculdade de Filosofia. This agreement lasted for more than a decade.

In the seventies, Luiz de Oliveira finished his doctoral thesis as a graduate student of the Pharmacology Department of the Medical School. From then on up to his untimely death, his efforts were directed to the laboratory in which the behavioral exercises were carried out year after year and his academic interest turned to malnutrition and its behavioral consequences. In the latter field, Luiz de Oliveira left a long heritage of students he counseled and research he published. Influenced by his research, later in life he helped create a nongovernmental organization dedicated to correct and prevent nutritional and correlated problems of babies from poor families who, otherwise, would not be able to deal with this problem. In 1977, after his post-doctoral studies with David Levitsky at Cornell University, USA, Luiz de Oliveira founded the Laboratory of Nutrition and Behavior in Ribeirão Preto, where he dedicated his entire life to the study of the interactions between the early effects of protein malnutrition on the brain and consequent behavioral alterations in adult life. His interests in the effects of environmental stimulation and environmental enrichment as effective procedures to alleviate brain and behavioral injuries produced by early protein malnutrition also conducted him to create the Multi-professional Center for the Study and Support of Children, dedicated to recover developmental impairment produced by malnutrition, among other risk factors.

It must not be forgotten, still, that his indefatigable disposition for teaching led him to participate in various forums related to the improvement of psychology teaching in Brazil. His determination to dedicate many hours to the study of the psychology curricular guidelines was associated to his long 


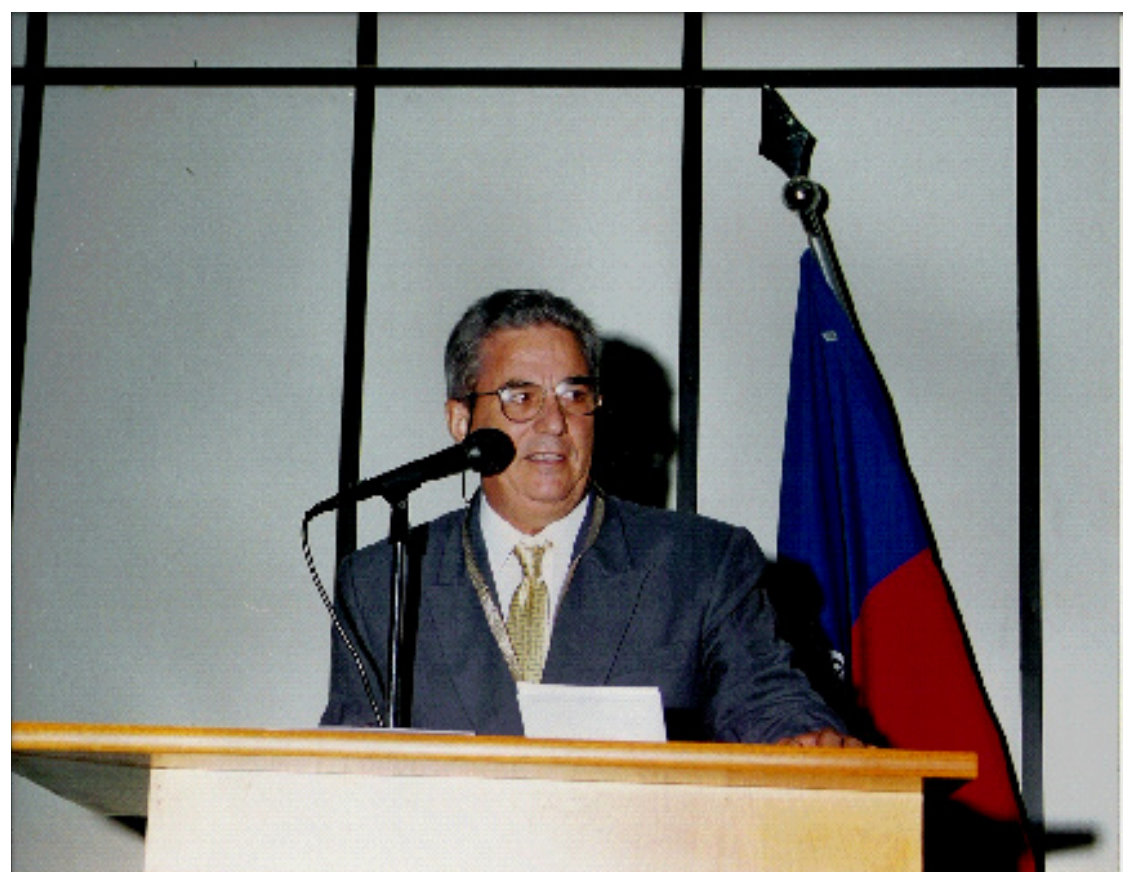

Figure 1. Luis Marcellino de Oliveira during his speech after receiving the Medal of Honor from the Academia de Ciências de Ribeirão Preto.

history of contributions to the scientific societies, especially the creation and consolidation of the Society of Psychology of Ribeirão Preto, predecessor of the Brazilian Psychology Society.

His interest in a multidisciplinary approach to the study of behavior was essential to integrate a group of researchers that proposed the creation of the PostGraduate Program in Psychobiology at the Department of Psychology of the Faculdade de Filosofia, Ciências e Letras de Ribeirão Preto - University of São Paulo, in the year of 1984. Undoubtedly, the national and international projection of the name of the Department of Psychology of Ribeirão Preto as an important center for the study of Psychobiology in Brazil, especially in the studies of malnutrition and behavior, is the result of the intense efforts conducted by Luiz de Oliveira and other dedicated researchers working at the Faculdade de Filosofia and other institutions.

Throughout his life, Luiz Marcellino de Oliveira strengthened friendship bonds with many people both from the university and outside. In a nutshell, he was a humanitarian who dedicated his professional life to education and to the research of the behavioral consequences of malnutrition. His presence shall be missed. 